\title{
O Envolvimento Parental Após a Separação/Divórcio
}

\author{
Parental Involvement After Separation/Divorce
}

\author{
Luciana Suárez Grzybowski ${ }^{*}, a$ \& Adriana Wagner ${ }^{b}$ \\ ${ }^{a}$ Universidade Comunitária da Região de Chapecó \\ ${ }^{b}$ Universidade Federal do Rio Grande do Sul
}

\begin{abstract}
Resumo
Apoiados no modelo ecológico-contextual e no conceito de envolvimento parental, este artigo se propõe a discutir as práticas parentais de pais e mães separados/divorciados com seus filhos. Para tanto, foram pesquisados 234 sujeitos (117 pais/117 mães) com filhos em idade escolar, que responderam o Inventário de Práticas Parentais. Tal instrumento avaliou o envolvimento parental em 5 áreas: envolvimento afetivo, envolvimento didático, envolvimento social, envolvimento disciplinar e responsabilidade. Os resultados evidenciam maior envolvimento materno do que paterno com os filhos após o divórcio, tanto direto (cuidados, interação) quanto indireto (monitoramento, preocupação). A coabitação com a mãe mostrou ser uma variável significativa associada ao maior envolvimento dela em atividades no espaço privado/ doméstico, enquanto os pais tiveram maior envolvimento no espaço público/social. Características contextuais (coabitação, freqüência de visitas) e características dos pais (ocupação, escolaridade, questões afetivo-conjugais) mostraram-se fortemente associadas ao envolvimento parental após o divórcio. Palavras-chave: Práticas parentais; Envolvimento parental; Divórcio; Pais; Mães.
\end{abstract}

\begin{abstract}
Based on the ecological-contextual model and on the concept of parental involvement, this article proposes to discuss the parental practices of separated/divorced fathers and mothers towards their children. In order to do so, 234 subjects (117 fathers/117 mothers) with children at school were interviewed via the Parental Practices Inventory. Such instrument evaluated the parental involvement in 5 areas: affective involvement, didactic involvement, social involvement, disciplinary involvement and, responsibility. The results showed greater maternal involvement with children after the divorce: direct (care, interaction) and indirect (monitoring, preoccupation). The cohabitation with the mother revealed itself as a significant variable associated to her greater involvement with activities in the private/domestic environment while fathers had greater involvement in the public/social space. Contextual characteristics (cohabitation, frequency of visits) and characteristics of the parents (occupation, education, affective and conjugal issues) showed to be strongly associated with the parental involvement after divorce.

Keywords: Parental practices; Parental involvement; Divorce; Fathers; Mothers.
\end{abstract}

As mudanças nas relações entre pais e filhos decorrentes das transformações pelas quais a família vem passando têm levado a um crescente questionamento sobre o papel dos pais e das mães na educação dos filhos. A importância da interação parental e das práticas educativas utilizadas pelos pais sobre o desenvolvimento de crianças e adolescentes tem sido tema de diversas pesquisas nas ultimas décadas (Baumrind, 1966, 1997;

* Endereço para correspondência: Rua Mal. Floriano Peixoto, 545/105, Jardim Itália, Chapecó, SC, Brasil, CEP 89801-500. Tel.: (49) 3328 3820; 84020088. E-mail: lugrzybowski@unochapeco.edu.br Este artigo é parte integrante da Tese de Doutorado em Psicologia da primeira autora, defendida em maio de 2007, na Pontifícia Universidade do Rio Grande do Sul (PUCRS), com bolsa da Coordenação de Aperfeiçoamento de Pessoal de Nível Superior (CAPES).
Chen, Liu, \& Li, 2000; Darling \& Steinberg, 1993; Maccoby \& Martin, 1983; Oliveira, Frizzo, \& Marin, 2000). Na revisão da literatura sobre o tema pode-se identificar duas dimensões distintas na interação de pais e filhos: as práticas educativas e os estilos parentais.

As práticas educativas parentais referem-se às estratégias utilizadas pelos pais para atingir objetivos específicos em diferentes domínios (acadêmico, social, afetivo) sob determinadas circunstâncias e contextos (Hart, Nelson, Robinson, Olsen, \& McNeilly-Choque, 1998). Visam orientar o comportamento dos filhos no sentido de fazer com que eles adquiram certos comportamentos e, também, para suprimir ou reduzir outros comportamentos considerados socialmente inadequados ou desfavoráveis (Grusec \& Lytton, 1988; Mussen, Conger, Kagan, \& Huston, 1990; Newcombe, 1999). 
Nos anos 60, a partir de investigações a respeito do tema, Hoffman (1960) considerava a existência de duas maneiras pelas quais os pais podem utilizar o seu poder para alterar o comportamento dos filhos: a primeira, através de uma disciplina indutiva, que objetiva uma modificação voluntária no comportamento da criança (através da indução, da lógica, da explicação acerca dos valores morais, do estímulo da empatia); e a segunda, através de técnicas que reforçam e reafirmam o poder parental, como práticas coercitivas (aplicação direta da força e poder dos pais, como punição física, ameaças e privação). Estes postulados ainda hoje sustentam e orientam muitas investigações sobre essa temática.

Já o estilo parental refere-se a um conjunto de práticas que constituem um padrão global de interação pais-filhos em diversas situações, gerando um clima emocional que perpassa as atitudes dos pais e cujo efeito é alterar a eficácia de práticas disciplinares específicas, além de influenciar a abertura ou predisposição dos filhos à socialização (Costa, Teixeira, \& Gomes, 2000; Darling \& Steinberg, 1993). Estilos parentais é uma classificação das práticas familiares que também surgiu na década de 60, proposta por Baumrind (1966), e que posteriormente foi ampliada por pesquisadores da Psicologia do Desenvolvimento (Lamborn, Mounts, Steinberg, \& Dornbusch, 1991), cujo instrumento para sua avaliação foi adaptado ao português por Costa et al. (2000).

Os estilos parentais são avaliados a partir de duas dimensões: responsividade e exigência parental. A dimensão responsividade refere-se às atitudes parentais que favorecem a individualidade e auto-afirmação dos filhos através do apoio e da aquiescência. Já a exigência, refere-se às atitudes parentais que requeiram supervisão e disciplina e que podem provocar confronto diante de desobediência. A partir dessas dimensões, os estilos parentais foram classificados em quatro grandes tipos: autoritário, autorizante, indulgente e negligente (Maccoby \& Martin, 1983).

Assim, pais com escores altos em ambas as dimensões são classificados como autorizantes; aqueles com escores baixos em ambas recebem a classificação de negligentes. Pais com escores altos em exigência, mas baixos em responsividade são denominados autoritários; por sua vez, pais com escores elevados em responsividade e baixos em exigência são considerados indulgentes (Costa et al., 2000).

Além desses modelos de compreensão das práticas educativas parentais (Baumrind, 1966; Hoffman, 1960), destaca-se o Modelo de Belsky (1978, 1979, 1980, 1981, 1984, 1990; Belsky, Steinberg, \& Draper, 1991). Este modelo propõe um sistema capaz de integrar diferentes pontos de vista na explicação deste fenômeno, integrando três instâncias fundamentais: as características dos pais, as características dos filhos e as características do contexto social. Belsky (1984) afirmava, já no início dos anos 80 , que do contexto fazem parte a rede de apoio social (como a escola e os amigos, por exemplo), a relação conjugal e as experiências ocupacionais dos pais, sendo que estas questões influenciam diretamente na funcionalidade da parentalidade e no desenvolvimento infantil. Este modelo baseia-se na ecologia do desenvolvimento humano proposta por Bronfenbrenner (1979/ 1996).

Além de ser um modelo integrador, ele tem sido considerado como tendo um caráter preventivo. Isso porque algumas relações entre as três dimensões (pais/filhos/ contexto) auxiliam no desenvolvimento de competências psicossociais, que protegem e reduzem a vulnerabilidade de crianças e adolescentes (Reppold, Pacheco, Bardagi, \& Hutz, 2002).

Belsky (Belsky et al., 1991; Belsky, Domitrovich, \& Crnic, 1997), ao destacar a importância das características individuais dos filhos, possibilita ampliar a visão do fenômeno educativo, geralmente centralizado nas características dos pais. Assim, passa a ter importância os diferentes padrões de interação entre pais e filhos e seus efeitos sobre o desenvolvimento dos mesmos, em diferentes contextos sociais. Ele enfatiza a necessidade de se investigar a satisfação conjugal, a satisfação profissional dos pais e a sua rede de apoio social.

Dessa forma, ele traz um modelo de parentalidade multi-determinado, que foge da simplificação de alguns modelos teóricos, e realiza uma análise mais complexa e rigorosa das práticas educativas e de socialização da família. Compreender essa complexidade é fundamental para dar suporte e orientação adequados às famílias na educação de seus filhos (Rodrigo \& Palácios, 2003), uma vez que o processo de socialização da criança é resultado da interação de diversos níveis ou fatores que necessitam de abordagens multidimensionais do contexto familiar (Benetti \& Balbinoti, 2003).

Passadas duas décadas da atualização do modelo, novas formas de compreensão da parentalidade vêm sendo propostas. Tem se falado em envolvimento parental (Lamb, Pleck, Charnov, \& Levine, 1985) e atitude parental (Karpinski \& Hilton, 2001). O envolvimento pode ser de natureza direta, referindo-se a todas as formas de interação direta com a criança, nas formas de cuidado em geral, brincadeiras ou tempo livre com ela, ou de natureza indireta, através da acessibilidade e da responsabilidade pelo bem-estar da mesma (saúde, escola, sustento). Já a atitude parental é concebida como resultado de três componentes: o cognitivo (crenças dos pais), o afetivo e o comportamental (interação).

$\mathrm{O}$ envolvimento parental tem sido mais utilizado para se referir ao envolvimento paterno, a partir de uma análise qualitativa da participação dos pais (homens), a qual foi, durante muito tempo, estudada numa perspectiva quantitativa, sem atentar para o conteúdo dessa dimensão (Pleck, 1997). A ideia, que nasceu em função do aumento do número de divórcios, era verificar o quanto os pais não-residentes reduziam sua participação na vida 
dos filhos. Porém, a partir do final da década de 90, deu lugar ao interesse pela qualidade e pelo conteúdo do envolvimento paterno.

Nessa perspectiva, este estudo objetiva investigar as práticas parentais de pais e mães separados/divorciados com seus filhos. Ao enfocar especificamente a família com pais divorciados, buscou-se conhecer como se dava o envolvimento ou engajamento do pai e da mãe na vida da criança.

Nesse sentido, pesquisas têm indicado que a mulher é a maior responsável pelos filhos após o divórcio, ficando sobrecarregada, e muitas vezes, solitária na tarefa de educar os filhos (Grzybowski, 2002; Marin, 2005; Wagner, 2002). Por outro lado, estudos atestam que um padrão comum para os pais não-residentes (que são a maioria no divórcio, pois a guarda é maciçamente da mãe) é se tornarem desapegados de seus filhos, desenvolvendo uma relação de visitantes, baseada em recreação e contatos sociais (Thompson \& Laible, 1999).

Dessa forma, é plausível pensar que o status conjugal pode ter implicações no relacionamento pais-filhos, com consequiências nas práticas educativas utilizadas nas famílias (Marin, 2005). O uso de práticas educativas parentais pode variar em diferentes contextos, sendo importante investigar as eventuais diferenças nas práticas educativas maternas e paternas em famílias divorciadas.

Poucos são os estudos que têm se preocupado em examinar as práticas educativas em diferentes configurações familiares. Entretanto, a ausência de um dos pais (como no caso da separação) pode levar a diferenças nos níveis de autoritarismo ou negligência dos progenitores ou, ainda, nos índices de envolvimento e supervisão parental (Biblarz \& Gottainer, 2000; Marin, 2005).

Pretende-se, então, conhecer quais são as práticas utilizadas, o tipo de envolvimento parental exercido e as possíveis diferenças de envolvimento do pai e da mãe com seus filhos. Para fins de análise, utilizou-se como referência principal o Modelo de Belsky (1984) e o conceito de envolvimento parental (Lamb et al., 1985), referidos na literatura.

\section{Método}

\section{Participantes}

Participaram deste estudo 234 sujeitos, sendo 117 pais e 117 mães separados/divorciados (com ruptura do vínculo conjugal, independentemente do status civil), com pelo menos um dos filhos em idade escolar (6 a 12 anos).

\section{Instrumento}

Os pais e mães divorciados deste estudo responderam o instrumento "Inventário de Práticas Parentais" (Benetti \& Balbinotti, 2002). Este inventário (IPP) foi construído para avaliar as práticas parentais, considerando o envolvimento afetivo, a didática (educação), a disciplina, os aspectos sociais e a responsabilidade do envolvimento parental. O Inventário completo possui 29 itens de avaliação, que se constituem em frases afirmativas, que devem ser respondidas numa escala tipo Lickert de 5 pontos (muito freqüentemente, freqüentemente, algumas vezes, raramente, nunca). Este instrumento teve suas propriedades psicométricas consideradas satisfatórias no estudo conduzido por Benetti e Balbinotti (2003), da mesma forma que no estudo piloto realizado para esta pesquisa (Grzybowski, 2005). Com os dados desta pesquisa, foi calculado o alfa de Cronbach, que teve um coeficiente de 0,903 , evidenciando a confiabilidade do mesmo. Neste estudo optou-se por utilizar a versão completa, uma vez que ela inclui a dimensão responsabilidade, que avalia aspectos do envolvimento parental indireto, considerado importante categoria de análise no estudo das práticas parentais.

Juntamente ao instrumento, os pais e mães preencheram uma ficha de dados biodemográficos, que investigava diversas variáveis consideradas associadas ao fenômeno pela literatura: idade, ocupação, classe social, escolaridade, tempo de separação, tipo de separação, auxílio financeiro do ex-companheiro, avaliação da relação com o ex-companheiro, recasamento, quantidade de filhos, idade dos filhos, coabitação, frequência de visitas, outros filhos de outros relacionamentos e apoio no cuidado dos filhos.

\section{Procedimentos de Coleta dos Dados}

Os pais e mães divorciados participantes foram selecionados em escolas estaduais e particulares de Porto Alegre e Região Metropolitana, bem como identificados pessoalmente pelas pesquisadoras, conforme contato por conveniência, utilizando método não-probabilístico. Todos foram informados e esclarecidos sobre o estudo e as questões éticas envolvidas no mesmo, assinando o Termo de Consentimento Livre e Esclarecido.

\section{Procedimentos de Análise dos Dados}

Com o auxilio do pacote estatístico SPSS versão 11.0, foram realizadas diversas análises. Uma análise estatística descritiva (frequiência, médias e percentuais) das variáveis estudadas (dados biodemográficos e práticas educativas), considerando as 5 dimensões do inventário (Social, Didática, Disciplina, Afetivo-Suporte Emocional e Responsabilidade). Além disso, buscou-se identificar diferenças entre as médias de pais e mães no IPP (gerais e por dimensão), utilizando-se o teste $t$ de Student, bem como entre as médias de pais e mães em cada uma das sentenças do IPP, utilizando-se do teste de MannWhitney. Também buscou-se verificar a associação entre as práticas parentais utilizadas (médias por dimensão) e algumas variáveis biodemográficas da pesquisa, através da realização da análise da variância (ANOVA - KruskalWallis Test). 


\section{Resultados e Discussão}

Quanto aos dados biodemográficos da amostra, algumas questões merecem destaque. Para tanto, serão apresentadas 3 tabelas que expõem as características da amostra, divididas em Dados de Identificação, Relação com o ex-cônjuge e Relação com os filhos.

Tabela 1

Dados de Identificação dos Participantes

\begin{tabular}{lll}
\hline & Pais $\quad(\mathrm{N}=117)$ & Mães $\quad$ (N=117) \\
\hline Idade média & 42,41 & 39,00 \\
Ocupações & Prof. Liberal: $24,79 \%$ & Prof. Liberal: $35,04 \%$ \\
& Comércio: $21,37 \%$ & Comércio: $4,27 \%$ \\
& Funcionário Público: $32,48 \%$ & Funcionário Público: $17,95 \%$ \\
& Professor: $20,51 \%$ & Professor: $26,50 \%$ \\
& Administrativo: $0,85 \%$ & Administrativo: $13,68 \%$ \\
& Não trabalha: $0 \%$ & Não trabalha: $2,56 \%$ \\
Escolaridade & Ensino Fundamental: $3,42 \%$ & Ensino Fundamental: $11,11 \%$ \\
& Ensino médio: $55,55 \%$ & Ensino médio: $50,43 \%$ \\
& Ensino superior: $34,19 \%$ & Ensino superior: $30,77 \%$ \\
Classe social que & Pós-graduação: $6,84 \%$ & Pós-graduação: $7,69 \%$ \\
acha que pertence & Média Alta: $7,67 \%$ & Média Alta: $19,66 \%$ \\
& Média: $60,69 \%$ & Média: $52,14 \%$ \\
Média Baixa: $31,62 \%$ & Média Baixa: $27,35 \%$ \\
Tempo médio & & Baixa: $0,85 \%$ \\
de separação & 4,58 & 4,00 \\
& &
\end{tabular}

A idade média dos pais e mães pesquisados foi de 40,7 anos, representando uma amostra jovem de progenitores. Existem mais pais trabalhando como funcionários públicos e no comércio, e mais mães que são profissionais liberais e têm cargos administrativos. A escolaridade predominante da amostra como um todo foi o ensino médio $(52,9 \%)$, mas houve um bom número de participantes com ensino superior $(32,47 \%)$. A maioria dos participantes $(56,41 \%)$ acredita que pertence à classe média.

O tempo médio de separação ou divórcio ficou em 4 anos, o que pode ser considerado um tempo adequado ou suficiente para a superação dos momentos mais difíceis pós-divórcio, conforme indicam os pesquisadores da temática (Grzybowski, 2002).

Tabela 2

Relação com o Ex-Cônjuge/Recasamento

\begin{tabular}{lll}
\hline & Pais $\quad(\mathrm{N}=117)$ & Mães $\quad(\mathrm{N}=117)$ \\
\hline Tipo de separação & Amigável: $37,61 \%$ & Amigável: $30,77 \%$ \\
& Conflituosa: $62,39 \%$ & Conflituosa: $69,23 \%$ \\
Tem auxílio financeiro do ex & Sim: $0 \%$ & Sim: $62,39 \%$ \\
& Não: $100 \%$ & Não: $37,61 \%$ \\
Avaliação relação com o ex & Boa: $18,80 \%$ & Boa: $23,08 \%$ \\
& Média: $50,43 \%$ & Média: $52,99 \%$ \\
Ruim: $30,77 \%$ & Ruim: $23,93 \%$ \\
& Sim: $61,54 \%$ & Sim: $41,03 \%$ \\
& Não: $38,46 \%$ & Não: $58,97 \%$ \\
\hline
\end{tabular}


Do total de participantes, $34,18 \%$ consideraram que a separação foi amigável e quase o dobro $(65,81 \%)$ a consideram conflituosa, sem haver diferenças significativas entre pais e mães. Mais da metade dos participantes, no entanto, classificaram sua relação com o ex-companheiro como de qualidade média $(51,70 \%)$, sendo que o restante se divide entre uma avaliação positiva $(20,94 \%)$ e negativa $(27,35 \%)$, tanto na opinião dos homens como na das mulheres.

Tabela 3

Relação com os Filhos

\begin{tabular}{lll}
\hline & Pais $(\mathrm{N}=117)$ & Mães $(\mathrm{N}=117)$ \\
\hline Número de filhos & 2,06 & 1,95 \\
Idade média dos filhos & 8,32 & 8,41 \\
Mora com filhos daquela união & Sim: $5,13 \%$ & Sim: $100 \%$ \\
& Não: $94,87 \%$ & Não visito, moro junto: $5,13 \%$ \\
Freqüência das visitas & Mais de 1 vez semana: $14,53 \%$ & \\
& 1 vez por semana: $14,53 \%$ & \\
& quinzenal: $37,61 \%$ & \\
& 1 vez por mês: $15,38 \%$ & \\
& a cada 2 meses: $1,71 \%$ & \\
& a cada 6 meses: $9,40 \%$ & Sim: $28,21 \%$ \\
Outros filhos de outros relacionamentos & Nim: $30,77 \%$ ano: $1,71 \%$ & Não: $71,79 \%$ \\
& Não visito, moro junto: $100 \%$ & Sim: $65,81 \%$ \\
Recebe apoio nos cuidados dos filhos & Sim: $65,81 \%$ & Não: $34,19 \%$
\end{tabular}

A média de filhos ficou em dois, sendo que a idade média dos mesmos foi de 8 anos. Todas as mães participantes do estudo residem com seus filhos e apenas seis pais coabitam com os mesmos, refletindo um arranjo familiar mais encontrado entre a realidade das famílias pós-divórcio.

Nesse sentido, a frequiência de visitas dos pais aos filhos apresentou-se bastante distribuída entre os intervalos apresentados. Entretanto, observa-se que os intervalos que referem-se a maior frequiência de visitas (mais de uma vez por semana, uma vez por semana e quinzenal) concentraram os maiores índices de respostas dos pais. Este fato pode representar, isoladamente, um maior envolvimento dos pais, embora saibamos que a frequiência de visitas não é suficiente para avaliarmos o conteúdo e a qualidade da relação parental que se estabelece.

A grande maioria de pais e mães não teve outros filhos de outros relacionamentos (70,51\%). Tanto os pais quanto as mães referiram ter apoio social para cuidar dos filhos $(65,81 \%)$, embora ainda $34,18 \%$ da amostra ter revelado carência deste suporte.
É maior o número de pais do que o de mães que recasaram (pais $=61,54 \%$; mães $=41,03 \%$ ). Todos os homens declararam não receber nenhum apoio financeiro da ex-cônjuge, enquanto mais da metade das mulheres investigadas o recebem $(62,39 \%)$. Também aqui algo tradicional da constelação pós-divórcio se expressa, uma realidade na qual, mais comumente, são os homens são os que pagam e não os que recebem pensão de suas exmulheres. Deve-se considerar, entretanto, que a maioria das mulheres são as detentoras da guarda dos filhos, conforme a tabela a seguir evidencia: 
Tabela 4

Comparação das Médias nas Áreas do IPP entre Pais e Mães

\begin{tabular}{lccc}
\hline Dimensões & Média dos pais & Média das mães & $\mathrm{p}(\mathrm{p} £ 0,05) *$ \\
\hline Envolvimento Social & 19,93 & 23,26 & $0,0001^{*}$ \\
Envolvimento Didático & 18,05 & 24,49 & $0,0001^{*}$ \\
Envolvimento com Disciplina & 13,63 & 18,23 & $0,0001^{*}$ \\
Envolvimento Afetivo & 24,22 & 31,88 & $0,0001^{*}$ \\
Responsabilidade & 10,44 & 16,08 & $0,0001^{*}$ \\
\hline
\end{tabular}

Assim como no escore geral do IPP, também nas médias por áreas do instrumento, as mães obtiveram médias significativamente superiores a dos pais em todas as dimensões. Tal resultado corrobora o explicitado anteriormente, ou seja, as mães desta pesquisa se mostraram mais envolvidas com seus filhos do que os pais. Se considerarmos que todas coabitam com as crianças, tal resultado desenha um cenário já conhecido, no qual a coabitação leva a um maior envolvimento direto com as crianças.

Tabela 5

Comparação entre as Médias de Pais e Mães nos Itens do IPP

\begin{tabular}{|c|c|c|c|c|}
\hline \multirow{2}{*}{$\begin{array}{l}\text { Envolvimentc } \\
\text { Parental }\end{array}$} & \multirow[t]{2}{*}{ Questões } & \multicolumn{2}{|c|}{ Médias } & \multirow{2}{*}{$\underset{(p £ 0,05)}{\mathrm{p}} *$} \\
\hline & & pai & mãe & \\
\hline \multirow[t]{6}{*}{ Social } & Participo de jogos com meu filho & 76,21 & 158,79 & $0,0001 *$ \\
\hline & Levo para fazer compras comigo & 106,94 & 128,06 & $0,012 *$ \\
\hline & Eu levo meu filho para o parque & 163,26 & 71,74 & $0,0001 *$ \\
\hline & Assisto TV/Escuto música & 70,33 & 164,67 & $0,0001 *$ \\
\hline & Levo meu filho ao cinema & 138,35 & 96,65 & $0,0001 *$ \\
\hline & Eu levo meu filho junto quando visito amigos & 62,86 & 172,14 & $0,0001 *$ \\
\hline \multirow[t]{6}{*}{ Didático } & Eu leio livros para meu filho & 67,64 & 167,36 & $0,0001 *$ \\
\hline & Eu converso sobre assuntos que ela/ele precisa saber sobre a vida & 99,88 & 135,12 & $0,0001 *$ \\
\hline & Eu ensino ao meu filho as matérias que ele não entende na escola & 67,39 & 167,61 & $0,0001 *$ \\
\hline & Eu converso com ela/ele sobre religião & 115,53 & 119,47 & 0,378 \\
\hline & Eu ajudo com os deveres escolares & 64,00 & 171,00 & $0,0001 *$ \\
\hline & Eu converso com meu filho sobre meu trabalho e as coisas que eu faço & 114,41 & 120,59 & 0,427 \\
\hline \multirow[t]{5}{*}{ Disciplina } & Eu grito com meu filho quando ele faz alguma coisa errada & 65,78 & 169,22 & $0,0001 *$ \\
\hline & Quando falar não é suficiente, eu dou palmadas no meu filho & 70,20 & 164,80 & $0,0001 *$ \\
\hline & As conversas com meu filho terminam em discussão & 97,26 & 137,74 & $0,0001 *$ \\
\hline & Eu ameaço colocar de castigo mas termino não fazendo nada & 75,64 & 159,36 & $0,0001 *$ \\
\hline & É muito difícil para mim fazer com que ele me obedeça & 127,83 & 107,17 & $0,006^{*}$ \\
\hline \multirow[t]{8}{*}{ Afetivo } & Eu tenho conversas amigáveis com meu filho & 118,15 & 116,85 & 0,874 \\
\hline & Eu converso sobre o que acontece na escola & 118,10 & 116,90 & 0,880 \\
\hline & Eu abraço e beijo meu filho & 91,40 & 143,60 & $0,0001 *$ \\
\hline & Eu digo a ele o quanto eu o amo & 95,38 & 139,62 & $0,0001 *$ \\
\hline & Eu conheço os amigos do meu filho & 62,45 & 172,55 & $0,0001 *$ \\
\hline & Eu me sinto muito próximo do meu filho & 60,71 & 174,29 & $0,0001 *$ \\
\hline & Só olhar pra ele é suficiente pra saber se ele está incomodado & 66,58 & 168,42 & $0,0001 *$ \\
\hline & Eu elogio meu filho & 104,83 & 130,17 & $0,002 *$ \\
\hline \multirow{4}{*}{$\begin{array}{l}\text { Responsa- } \\
\text { bilidade }\end{array}$} & Não importa a hora do dia eu sei onde meu filho está & 59,94 & 175,06 & $0,0001 *$ \\
\hline & Eu levo meu filho no médico quando é necessário & 64,26 & 170,74 & $0,0001 *$ \\
\hline & Eu converso com meu ex-esposo/companheiro/a sobre o futuro do meu filho & 124,37 & 110,63 & 0,083 \\
\hline & Eu posso estar ocupado, mas ele sabe onde me encontrar se precisar de algo & 68,81 & 166,19 & $0,0001 *$ \\
\hline
\end{tabular}

Utilizando-se do teste de Mann-Whitney, foi possível calcular se havia diferenças entre pais e mães para cada sentença do IPP, o que significa avaliar as diferenças entre pais e mães quanto às práticas educativas e envolvimento parental, permitindo especificar as diferenças entre os grupos nas 5 dimensãoes avaliadas. Tal cálculo foi realizado com o objetivo de compreender melhor quais as práticas educativas utilizadas pelos grupos com maior predominância, identificar qual dos grupos (pais ou mães) tiveram médias superiores e detalhar as práticas de cada área do IPP. 
As mães evidenciaram maior envolvimento com os filhos em todas as dimensões do inventário, bem como na maioria dos itens, quando analisados individualmente.

Nas dimensões Envolvimento Afetivo e Envolvimento Didático, os pais não obtiveram, em nenhuma variável, médias superiores as das mães. Foram nessas dimensões que, em 4 variáveis ( 2 em cada), não houve diferenças significativas entre as médias de pais e mães, relacionadas a conversar com os filhos. Diante disso, pode-se perceber que as mães deste estudo, quando comparadas aos pais, evidenciam maior envolvimento com seus filhos no que diz respeito ao suporte emocional (abraçar, beijar, dizer que ama, conhecer os amigos, sentir-se próxima, conhecer o jeito do filho) e ao suporte relacionado ao conhecimento/escola (ler livros para o filho, conversar sobre a vida, ensinar matérias da escola, ajudar nos deveres escolares).

Em relação à conversa com o filho, pais e mães demonstraram que não possuem diferenças significativas entre si, tendo médias semelhantes, o que evidencia que ambos estão conseguindo dialogar de forma igualitária em relação à religião, o seu trabalho, a escola e conversas amigáveis. A coabitação, que parece estar associada ao maior envolvimento da mãe no sentido emocional e didático (suporte afetivo e acompanhamento escolar), aqui parece não ser determinante para uma relação de diálogo e conversas entre pais e filhos.

Nas demais dimensões, encontram-se médias superiores dos pais em relação às mães em 3 variáveis, sendo 2 no Envolvimento Social (levar no cinema e no parque) e 1 no Envolvimento com Disciplina (dificuldade em fazer o filho obedecer). Estes resultados fazem pensar que os pais superam as mães no que diz respeito à recreação e lazer em contextos extra-lar, pois dentro de casa ou nas relações próximas, a mãe também evidencia maior envolvimento (jogos, ver TV, ouvir músicas). Talvez isso possa ser explicado pelo fato de a amostra ser predominante de pais não-residentes, o que muitas vezes pode determinar uma relação desenvolvida em espaços públicos.

No Envolvimento com Disciplina, as mães apresentam médias superiores as dos pais em todas as variáveis, com exceção de uma. Porém, como todas as sentenças são de conotação negativa ou de problemas com as práticas educativas (eu grito, dou palmadas, discuto, ameaço, tenho dificuldades), é necessário analisar com cautela a diferença entre pais e mães. As médias superiores das mães evidenciam que elas se envolvem mais com a disciplina de seus filhos, porém também podem demonstrar que elas têm dificuldades nessa função, talvez pela exigências educacionais cotidianas e imediatas. Assim como o fato dos pais terem médias mais baixas, pode revelar um menor envolvimento com a disciplina, a média mais alta que as mães no item referente à dificuldade em fazer com que o filho lhe obedeça, pode revelar um enfraquecimento no que se refere ao seu papel de autoridade.

Em relação à Responsabilidade, que corresponde àquela dimensão que visa avaliar o envolvimento indireto, ou seja, o envolvimento relacionado à preocupação, supervisão e zelo com o bem-estar do filho, as mães também tiveram médias significativamente superiores a dos pais em quase todas as variáveis, com exceção de uma. Tanto os homens como as mulheres referiram conseguir conversar com seus ex-companheiros/as sobre o futuro dos filhos, o que talvez indique a preservação desta nuance da função coparental, mesmo posteriormente à ruptura conjugal. Porém, cabe ressaltar, que as mães mostraram que estão mais atentas à rotina dos filhos (eu sei onde meu filho está), disponíveis (ele sabe onde me encontrar se precisar de algo) e zelosas (eu levo ele no médico).

A fim de delimitar quais as variáveis que estão associadas ao envolvimento parental, comparou-se os dados biodemográficos de pais e mães com os escores das áreas do IPP, através da análise da variância (ANOVA). Os níveis de significância encontram-se na Tabela 6 .

Tabela 6

ANOVA (Kruskal-Wallis Test) das Dimensões do IPP entre os Dados Biodemográficos dos Pais e das Mães - " $p$ value" $(p £ 0,05)$

\begin{tabular}{|c|c|c|c|c|c|c|c|c|c|c|c|c|}
\hline & \multicolumn{2}{|c|}{ Env.social } & \multicolumn{2}{|c|}{ Env.didático } & \multicolumn{2}{|c|}{ Env.disciplina } & \multicolumn{2}{|c|}{ Env.afetivo } & \multicolumn{2}{|c|}{ Responsabilidade } & \multicolumn{2}{|c|}{ Global } \\
\hline & $\mathrm{P}$ & M & $\mathrm{P}$ & M & $\mathrm{P}$ & $\mathrm{M}$ & $\mathrm{P}$ & M & $\mathrm{P}$ & M & $\mathrm{P}$ & M \\
\hline Freqüência visitas & $0,034 *$ & - & $0,000^{*}$ & - & $0,000 *$ & - & $0,000^{*}$ & - & $0,000 *$ & - & $0,000 *$ & - \\
\hline Ocupação & 0,102 & $0,034 *$ & 0,499 & $0,000^{*}$ & 0,188 & 0,271 & $0,003 *$ & 0,052 & $0,012 *$ & $0,012 *$ & $0,013 *$ & $0,000 *$ \\
\hline Escolaridade & $0,024 *$ & 0,855 & 0,575 & $0,030 *$ & 0,415 & 0,909 & 0,525 & 0,309 & 0,882 & 0,413 & 0,486 & 0,427 \\
\hline Relação com ex & 0,282 & 0,898 & 0,226 & 0,999 & $0,006^{*}$ & 0,217 & 0,621 & 0,941 & 0,727 & 0,994 & 0,793 & 0,598 \\
\hline Classe Social & 0,165 & 0,124 & 0,402 & 0,828 & 0,562 & 0,408 & 0,876 & 0,150 & 0,835 & 0,259 & 0,585 & 0,073 \\
\hline Idade & 0,662 & 0,319 & 0,651 & 0,485 & 0,744 & 0,810 & 0,523 & 0,386 & 0,133 & 0,793 & 0,859 & 0,598 \\
\hline Tempo de Separação & 0,671 & 0,940 & 0,824 & 0,675 & 0,361 & 0,341 & 0,511 & 0,279 & 0,764 & 0,607 & 0,974 & 0,979 \\
\hline Tipo de Separação & 0,078 & 0,072 & 0,123 & $0,010 *$ & 0,600 & $0,008^{*}$ & 0,716 & 0,406 & $0,040 *$ & 0,382 & 0,137 & $0,033 *$ \\
\hline Quantidade de filhos & 0,953 & 0,942 & 0,581 & 0,681 & 0,444 & 0,435 & 0,607 & 0,077 & 0,067 & 0,099 & 0,465 & 0,191 \\
\hline Idade dos filhos & 0,662 & 0,319 & 0,651 & 0,485 & 0,744 & 0,810 & 0,523 & 0,386 & 0,133 & 0,793 & 0,859 & 0,598 \\
\hline Recasamento & 0,586 & 0,076 & 0,395 & 0,615 & $0,034 *$ & 0,482 & 0,143 & 0,432 & 0,274 & 0,250 & 0,109 & 0,382 \\
\hline Apoio Social & 0,410 & 0,702 & 0,147 & 0,599 & 0,193 & 0,633 & 0,653 & 0,153 & 0,186 & 0,079 & 0,535 & 0,853 \\
\hline Auxílio Financeiro & - & 0,211 & - & 0,232 & - & 0,577 & - & 0,614 & - & 0,839 & - & 0,077 \\
\hline Coabitação & $0,019 *$ & - & $0,000 *$ & - & $0,000 *$ & - & $0,000 *$ & - & $0,000^{*}$ & - & $0,000^{*}$ & - \\
\hline
\end{tabular}


Observando-se os dados da tabela abaixo, é possível perceber que as variáveis classe social, idade, tempo de separação, quantidade de filhos, idade dos filhos, apoio social e auxílio financeiro, não apresentaram relação estatisticamente significativa com a variação dos níveis de envolvimento de pais e mães nas diferentes dimensões do IPP.

Duas variáveis, em especial, evidenciaram associação significativa em todas as dimensões do envolvimento parental dos pais: freqüência de visitas e coabitação. Entretanto, é importante salientar que todas as mães do estudo têm a guarda dos filhos e apenas seis pais a possuem, portanto, a variável coabitação interfere significativamente nas demais. Ou seja, o fato destes pais não morarem com seus filhos influencia significativamente no menor envolvimento parental com eles. Os resultados apontam para algo muito discutido na literatura sobre envolvimento paterno pós-divórcio, que se refere à relação estreita entre esse constructo e a coabitação. Nesta pesquisa, a freqüência de visitas paternas também apresentou variação associada à oscilação do envolvimento parental, reforçando a idéia de relação entre visitar os filhos com mais freqüência (estar mais próximo) e se envolver mais com ele nas práticas parentais educativas. Além disso, tal resultado também nos leva a pensar que a coabitação materna tem relação direta com o nível de envolvimento parental e que, se o cenário fosse outro (guarda paterna), os resultados poderiam ser diferentes. De qualquer forma, tais resultados evidenciam a importância da convivência e a impossibilidade de ser pai ou mãe "virtuais".

A ocupação das mães mostrou associação com o seu envolvimento social, didático e global com os filhos, o que pode estar relacionado à especificidade do trabalho da mulher (carga horária, sobrecarga, demandas da função) e às consequiências do mesmo na sua rotina familiar. Da mesma forma, a ocupação relacionou-se com o envolvimento geral dos pais/homens com seus filhos, bem como no envolvimento afetivo e na responsabilidade. A hipótese explicativa levantada sobre as mães também poder ser válida para os pais, pois a frequiência das visitas pode ser influenciada pela ocupação deles. Pais com trabalhos muito envolventes, com grande número de horas de trabalho semanal, provavelmente, são aqueles que estão com mais dificuldades de envolverem-se com seus filhos, em especial afetivamente, pois este envolvimento parece ter uma interferência maior da variável ocupação.

A escolaridade apareceu relacionada ao envolvimento didático do pai, mostrando que variações no nível de escolaridade paterna repercutem em oscilações no envolvimento do pai com tarefas escolares dos filhos. No caso das mães, a escolaridade associou-se ao envolvimento social, o que talvez possa estar relacionado ao entendimento diferenciado da importância do lazer, cultura e entretenimento. Nesse sentido, os pais têm se envolvido mais, talvez por terem essa compreensão ou mesmo por priorizarem esses aspectos na relação com o filho após a separação, conforme as variáveis do inventário apontaram (levar no parque e no cinema).

Para os pais/homens, a relação com a ex-mulher influencia o envolvimento com a disciplina dos filhos. As variações na qualidade da relação conjugal desfeita se relaciona ao envolvimento com a disciplina do filho. $\mathrm{Da}$ mesma forma, o tipo de separação associou-se ao envolvimento didático, disciplinar e global das mães, e a responsabilidade e envolvimento global dos pais, corroborando a ideia de interdependência entre os subsistemas conjugal e parental. Por outro lado, estas associações nos levam a pensar a respeito da extensão das repercussões da relação conjugal sob a parental.

Evidenciou-se que o recasamento está relacionado com o envolvimento dos pais/homens com disciplina. Diversos estudos referem que a nova companheira dos homens muitas vezes assume um papel materno para com os filhos dele, e pode assumir uma função mais vinculada à disciplina, ou mesmo, ajudá-lo nesta tarefa. Por outro lado, também pode-se pensar que o recasamento pode afastar ainda mais o pai dos filhos daquela união desfeita, uma vez que ele pode acabar envolvendo-se mais com o novo casamento/nova companheira e com outros possíveis filhos desta união. Este dado também corrobora a idéia da interferência das relações afetivas/amorosas com os ex-companheiros na parentalidade, em especial, no que diz respeito aos progenitores do sexo masculino.

Diante dos resultados, evidencia-se uma configuração tradicional do envolvimento parental após a separação/ divórcio, ou seja, maior envolvimento materno do que paterno após o fim do casamento. As mães evidenciaram maior envolvimento nas práticas educativas parentais do que os pais desta pesquisa, seja ele de caráter direto (cuidados, interação) ou de caráter indireto (monitoramento, preocupação).

Nas cinco dimensões avaliadas, as mães obtiveram médias superiores aos pais. $\mathrm{O}$ envolvimento emocional (suporte afetivo) e o envolvimento didático (escola/conhecimentos) mostraram-se significativamente superiores no grupo das mães. Entretanto, em relação a conversar com os filhos, ambos demonstraram equilíbrio na realização desta prática educativa. Além da questão relacionada à coabitação, pode-se pensar que o maior envolvimento afetivo e didático das mães se deva também às prerrogativas de gênero feminino, que historicamente têm determinado que as mães são as principais cuidadoras e responsáveis pela educação dos filhos. Além disso, podese supor que o fato delas recasarem menos freqüentemente que os homens favoreça essa dedicação maior aos filhos, embora isso não seja determinante.

Os resultados também demonstraram que os pais têm maior envolvimento social no que diz respeito a atividades no espaço público (parque, cinema), enquanto as mães se envolvem mais com isso no espaço privado (TV, mú- 
sica), o que evidencia o desempenho de uma função clássica da mulher no espaço doméstico e uma afirmação da parentalidade paterna no espaço social/público. O envolvimento com disciplina também mostrou-se como uma prerrogativa significativamente maior das mães, entretanto, os resultados tanto dos pais como das mães confirmam que essa tarefa educativa é árdua e com dificuldades inerentes, embora os pais/homens tenham demonstrado menos problemas que as mães com tal aspecto. O exercício da autoridade passa a ser desgastante para a mulher devido à intensidade da demanda cotidiana imposta pela coabitação com os filhos.

A responsabilidade, associada ao envolvimento indireto, também apresentou maior participação das mães, que pareceram estar mais conectadas com os filhos e suas necessidades na atualidade. Por outro lado, os pais evidenciaram maior preocupação com o futuro dos filhos do que elas.

Buscando encontrar justificativas ou associações para os níveis de envolvimento de pais e mães, constatou-se que alguns fatores relacionaram-se, nesta pesquisa, com a variação do envolvimento parental (coabitação, freqüência das visitas, ocupação, escolaridade, relação com o ex, tipo de separação e recasamento), enquanto outros (classe social, idade, tempo de separação, quantidade de filhos, idade dos filhos, apoio social e auxílio financeiro), não apresentaram relação estatisticamente significativa com a variação dos níveis de envolvimento de pais e mães nas diferentes dimensões do IPP.

Dentre aqueles que tiveram relação com diferentes tipos de envolvimento dos pais e/ou das mães, destaca-se aqui, a coabitação maciçamente feminina, que certamente influenciou os resultados. Também podemos pensar nas possíveis variações destas relações, ou seja, será que se os pais visitassem mais seus filhos a coabitação teria tanto peso quanto no envolvimento parental das mães?

Dessa forma, podemos observar que as características do contexto social (combinações de visitas, arranjos de moradia) e dos pais (ocupação, escolaridade, questões da conjugalidade) parecem ser importantes na determinação das práticas educativas parentais. Os arranjos de coabitação e visitação têm reflexos sob a parentalidade e o envolvimento parental, evidenciando a manutenção de padrões tradicionais de parentalidade divorciada, na qual há um maior envolvimento global das mães com seus filhos, à exceção do envolvimento social/público dos pais.

Porém, considerando o Modelo de Belsky (1984), pensamos que seria importante ouvir a opinião dos filhos sobre esse fenômeno, a fim de ampliar a compreensão do mesmo e não centralizar a avaliação da parentalidade apenas nos pais. Além disso, faz-se necessário também compreender tal fenômeno de forma qualitativa, buscando aprofundar o entendimento e a percepção de como as variáveis associadas ao envolvimento parental se manifestam no cotidiano das famílias e quais as justificativas para o maior ou menor envolvimento com os filhos após o advento do divórcio.

\section{Referências}

Baumrind, D. (1966). Effects of authoritative parental control on child behavior. Child Development, 37, 887-907.

Baumrind, D. (1997). The discipline encounter: Contemporany issues. Agression and Violent Behavior, 2, 321-335.

Belsky, J. (1978). Three theoretical models of child abuse: A critical review. International Journal of Child Abuse and Neglect, 2, 37-49.

Belsky, J. (1979). The interrelation of parental and spousal behavior during infancy in tradicional nuclear families: An exploratory analysis. Journal of Marriage and the Family, $41,62-68$.

Belsky, J. (1980). Child maltreatment: An ecological integration. American Psychologist, 35, 320-335.

Belsky, J. (1981). Early human experience: A family perspective. Developmental Psychology, 17, 3-23.

Belsky, J. (1984). The determinants of parenting: A process model. Child Development, 55, 83-96.

Belsky, J. (1990). Parental and nonparental child care and children's socioemotional development: A decade in review. Journal of Marriage and the Family, 52, 885-903.

Belsky, J., Domitrovich, C., \& Crnic, K. (1997). Temperament and parenting antecedents of individual differences in threeyear-old boy's pride and shame reactions. Child Development, 68, 456-466.

Belsky, J., Steinberg, L., \& Draper, P. (1991). Childhood experience, interpersonal development and reproductive strategy: An evolutionary theory of socialization. Child Development, 62, 647-670.

Benetti, S. P. C., \& Balbinotti, M. A. (2002). Inventário de práticas parentais. Manuscrito não-publicado, Universidade do Vale do Rio dos Sinos, São Leopoldo, RS.

Benetti, S. P. C., \& Balbinotti, M. A. (2003). Elaboração e estudo de propriedades psicométricas do Inventário de Práticas Parentais. Psico-USF, 8(2), 103-113.

Biblarz, T. J., \& Gottainer, G. (2000). Family structure and children's success: A comparison of widowed and divorced single-mother families. Journal of Marriage and Family, 62(2), 533-548.

Bronfenbrenner, U. (1996). A ecologia do desenvolvimento humano: Experimentos naturais e planejados. Porto Alegre, RS: Artes Médicas. (Original publicado em 1979)

Chen, X., Liu, M., \& Li, D. (2000). Parental warmth, control, and indulgence and their relations to adjustment in Chinese children: A longitudinal study. Journal of Family Psychology, 14(3), 401-419.

Costa, F. T., Teixeira, M. A., \& Gomes, W. B. (2000). Responsividade e exigência: Duas escalas para avaliar estilos parentais. Psicologia: Reflexão e Crítica, 13, 465-473.

Darling, N., \& Steinberg, L. (1993). Parenting style as a context: An integrative model. Psychological Bulletin, 113, 487-496.

Grusec, J. E., \& Lytton, H. (1988). Social development: History, theory and research. New York: Springer-Verlag.

Grzybowski, L. S. (2002). Famílias monoparentais: Mulheres divorciadas chefes de família. In A. Wagner (Ed.), Família em cena: Tramas, dramas e transformações (pp. 39-53). Rio de Janeiro, RJ: Vozes.

Grzybowski, L. S. (2005). Práticas educativas maternas e paternas e a coparentalidade após a separação/divórcio. Projeto de Tese de Doutorado não-publicado, Faculdade de Psicologia, Pontifícia Universidade do Rio Grande do Sul, Porto Alegre, RS. 
Hart, C. H., Nelson, D. A., Robinson, C. C., Olsen, S. F., \& McNeilly-Choque, M. K. (1998). Overt and relational aggression in Russian nursery-school-age children: Parenting styles and marital linkages. Developmental Psychology, 34, 687-697.

Hoffman, M. L. (1960). Power assertion by the parent and its impact on the child. Child Development, 31, 129-143.

Karpinski, A., \& Hilton, J. L. (2001). Attitudes and the Implicit Association Test. Journal of Personality and Social Psychology, 81(5), 774-788.

Lamb, M. E., Pleck, J. H., Charnov, E. L., \& Levine, J. A. (1985). Paternal behavior in humans. American Zoologist, 25, 883-894.

Lamborn, S. D., Mounts, N. S., Steinberg, L., \& Dornbusch, S. M. (1991). Patterns of competence and adjustment among adolescents from authoritative, authoritarian, indulgent and neglectful families. Child Development, 62, 1049-1065.

Maccoby, E., \& Martin, J. (1983). Socialization in the context of the family: Parent-child interaction. In P. H. Mussen (Series Ed.) \& E. M. Hetherington (Vol. Ed.), Handbook of Child Psychology: Vol. 4. Socialization, personality, and social development ( $4^{\text {nd }}$ ed., pp. 1-101). New York: Wiley.

Marin, A. H. (2005). Práticas educativas maternas em famílias de mães solteiras e famílias nucleares. Dissertação de Mestrado não-publicada, Instituto de Psicologia, Universidade Federal do Rio Grande do Sul, Porto Alegre, RS.

Mussen, P. H., Conger, J. J., Kagan, J., \& Huston, A. C. (1990). Child development \& personality. Nova York: Harper \& Row.

Newcombe, N. (1999). Desenvolvimento infantil: Abordagem de Mussen. Porto Alegre, RS: Artes Médicas.

Oliveira, E. A., Frizzo, G. B., \& Marin, A. H. (2000). Atitudes maternas diferenciais para com meninos e meninas de quatro e cinco anos. Psicologia Reflexão e Crítica, 13(3), 363371.

Pleck, J. H. (1997). Paternal involvement: Levels, sources, and consequences. In M. Lamb (Ed.), The role of the father in child development (pp. 66-103). New York: John Wiley \& Sons.

Reppold, C. T., Pacheco, J., Bardagi, M., \& Hutz, C. S. (2002). Prevenção de problemas de comportamento e o desenvolvimento de competências psicossociais em crianças e adolescentes: Uma análise das práticas educativas e dos estilos parentais. In C. S. Hutz (Ed.), Situações de risco e vulnerabilidade na infância e na adolescência: Aspectos teóricos e estratégias de intervenção (pp. 7-51). São Paulo, SP: Casa do Psicólogo.

Rodrigo, M. J., \& Palacios, J. (2003). Conceptos y dimensiones en el análisis evolutivo-educativo de la família. In M. J. Rodrigo \& Palácios, J. (Eds.), Família y desarollo humano (4. ed., pp. 45-70). Madrid, España: Alianza.

Thompson, R. S., \& Laible, D. J. (1999). Noncustodial parents. In M. Lamb (Ed.), Parenting and chil development in "nontradicional" families (pp. 103-123). Hillsdale, NJ: Lawrence Eribaum.

Wagner, A. (2002). Possibilidades e potencialidades da família: A construção de novos arranjos a partir do recasamento. In A. Wagner (Ed.), Família em cena: Tramas, dramas e transformações (pp. 23-38). Petrópolis, RJ: Vozes. 